\title{
Avaliação da integridade e da retenção de metais pesados em materiais estabilizados por solidificação
}

\author{
Assessment of integrity and retention of heavy metals in \\ materials stabilized by solidification
}

\begin{abstract}
André Luiz Fiquene de Brito
Químico pela Universidade Federal da Paraíba (UFPB). Mestre em Meio Ambiente e Desenvolvimento pela UFPB. Doutor em Engenharia Ambiental pela Universidade Federal de Santa Catarina (UFSC) e Professor da Universidade Federal de Campina Grande (UFCG)
\end{abstract}

Sebastião Roberto Soares

Engenheiro Sanitarista pela UFSC. Mestre e Doutor em Gestion et Traitement des Déchets pelo Institut National des Sciences Appliquées de Lyon, França. Pós-doutor pela École Polytechnique de Montreal (EPM) e Professor do Departamento de Engenharia Sanitária e Ambiental pela UFSC

\section{Resumo}

A quantidade de resíduos sólidos industriais tem aumentado significativamente em decorrência da industrialização, e o seu gerenciamento adequado é necessário para reduzir o impacto ao meio ambiente e aos ecossistemas. Neste trabalho, foram avaliadas a integridade e a retenção de metais pesados em materiais estabilizados por solidificação. Foi adotado o planejamento completamente aleatorizado com um único fator, ou seja, foram comparadas as médias de quatro tratamentos (A, B, C e D) com 0, 40, 50 e 60\% respectivamente de contaminantes e três repetições. Cimento Portland comum, bentonita sódica e hidróxido de cálcio foram usados para estabilizar por solidificação o resíduo sólido sintético contendo óxido de $\mathrm{Cd}^{2+}, \mathrm{Pb}^{2+}$ e $\mathrm{Cu}^{2+}$. Pode-se concluir que os tratamentos influenciaram no resultado de lixiviação do cádmio, chumbo e cobre. Os tratamentos mostraram que as concentrações do extrato solubilizado e lixiviado aumentam em função da quantidade de cádmio, chumbo e cobre adicionada. O maior valor encontrado foi para o material proveniente do tratamento D, que apresentou lixiviação igual a 32,815 mg. $\mathrm{kg}^{-1}$ para o cádmio e 29,769 mg. $\mathrm{kg}^{-1}$ para o chumbo. Para os ensaios de integridade/durabilidade, constatou-se que o aumento da absorção de água fez com que a resistência à compressão diminuísse. O uso de cimento, de hidróxido de cálcio e de bentonita sódica se mostrou ideal para retenção de metais pesados, evitando a sua lixiviação e a solubilização para o meio ambiente.

Palavras-chave: resíduos sólidos; protocolo de avaliação; metal pesado; estabilização por solidificação.

\begin{abstract}
As the quantity of hazardous industrial wastes increases significantly owing to rapid industrialization, its appropriate management is required to reduce adverse impacts on humans and ecosystems. This work evaluated the integrity and retention of heavy metals in materials stabilized by solidification. It was adopted a completely randomized design with a single factor, that is, the averages of four treatments were compared (A, B, C and D) with 0, 40,50 and 60\% respectively contaminants and three repetitions. Portland cement, bentonita and lime-fly ash binders were used to solidify a synthetic heavy metal sludge containing oxides of $\mathrm{Cd}^{2+}, \mathrm{Pb}^{2+}$ e $\mathrm{Cu}^{2+}$. It can be concluded that the treatment influenced the result of leaching of cadmium, lead and copper. The treatments showed that the concentrations of solubilized and leachate extract increase with the amount of cadmium, lead and copper added. The highest price was found in the material from the treatment $D$, that presented leaching equal to $32.815 \mathrm{mg} . \mathrm{kg}^{-1}$ for cadmium and $29.769 \mathrm{mg} . \mathrm{kg}^{-1}$ for the lead. For the tests of integrity/durability, it was found that increasing the absorption of water has caused resistance to compression decreased. The use of cement, calcium hydroxide and sodium bentonite were ideal for retention of heavy metals, avoiding leaching and solubilization for it's the environment.
\end{abstract}

Keywords: solid wastes; protocol for the evaluation; heavy metal; stabilization; solidification.

Endereço para correspondência: André Luiz Fiquene de Brito - Rua Osvaldo Cruz, 915 - Centenário - 58107-273 - Campina Grande (PB), Brasil - Tel.: (83) 9917-8708 - Fax: (83) 3310-1114 - E-mail: andre@deq.ufcg.edu.br

Recebido: 7/1/08 - Aceito: 10/12/08 


\section{Introdução}

A estabilização por solidificação (E/S) é uma forma de realizar o tratamento de resíduos e, para tanto, necessita do conhecimento das respostas ambientais e estruturais, em função da destinação preconizada. Tais respostas são obtidas basicamente pelo estudo das propriedades mecânicas e químicas do resíduo e pela simulação e modelagem, visando à extrapolação dos dados para longo prazo.

A Agência de Proteção Ambiental Norte-Americana (do inglês United States Environmental Protection Agency, USEPA) tem se referido a essa como "a melhor tecnologia disponível comprovada" regularizada para 57 tipos de resíduos nos Estados Unidos (SHI; SPENCE, 2004, p. 392).

A E/S constitui uma importante área das tecnologias ambientais, tendo sido considerada, por diversas vezes e em muitos relatórios governamentais e publicações cientificas, como a "melhor tecnologia disponível comprovada" (SHI; SPENCE, 2004, p. 408).

Geralmente, a E/S pode ser divida em processos inorgânicos (que levam agentes ligantes inorgânicos, como cimento e material pozolânico) e orgânicos (que levam agentes ligantes orgânicos, como polímeros termoplásticos e termofixantes). Alguns sistemas combinam agentes ligantes inorgânicos com orgânicos (ENVIRONMENTAL PROTECTION AGENCY, 1988). Os ligantes orgânicos que têm sido testados ou usados para E/S incluem asfalto, polietileno, poliésteres, polibutadieno, epóxido e uréia.

$\mathrm{Na}$ E/S, os contaminantes são aprisionados numa matriz sólida. Neste caso, a retenção do contaminante é limitada: i) pela diminuição da área de superfície exposta ao meio ambiente e/ou ii) pelo isolamento dos contaminantes da influência do meio externo por partículas presentes no resíduo (MALONE; JONES; LARSON, 1980). Spence e Shi (2005) informam que, na E/S, ocorrem reações químicas entre os contaminantes e aglomerantes e/ou retenção de natureza física.

A E/S é empregada como opção de pré-tratamento ou tratamento propriamente dito de resíduos sólidos perigosos que não podem

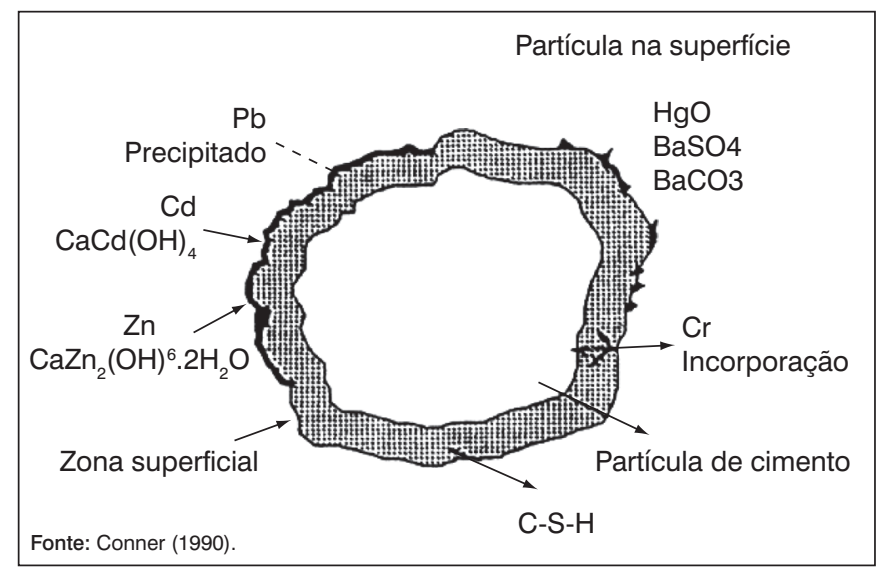

Figura 1 - Estabilização por solidificação de metais pesados por hidratação do cimento ser eliminados, reduzidos, reciclados ou utilizados no ambiente em que foram gerados na sua condição original (STEGEMANN; BUENFELD, 2003).

A imobilização de resíduos no processo E/S pode envolver mecanismos físicos, químicos, ou a combinação de ambos. A estabilização física (solidificação ou encapsulação) muda a forma física, mas não necessariamente causa ligação química dos constituintes do resíduo. A estabilização química muda os estados químicos dos constituintes do resíduo, transformando-os em formas menos solúveis em água.

A solidificação é um processo particular de estabilização de resíduos perigosos - daí o termo 'estabilização por solidificação'. Para exemplificar a retenção de alguns metais por E/S, podem ser mencionados os trabalhos de Conner (1990) e Wiles (1987), que trataram os resíduos sólidos industriais perigosos com pozolanas, cinzas volantes e cimento, mostrando como ocorre a conversão e aprisionamento dos contaminantes (Figura 1).

A Figura 1 retrata a definição de E/S, uma vez que os contaminantes estão retidos ou aprisionados no interior da partícula de cimento, além de ocorrerem reações químicas entre os contaminantes e aglomerantes e/ou processos de retenção física dos contaminantes.

$\mathrm{Na}$ Figura 1, chumbo $\left(\mathrm{Pb}^{2+}\right)$, cádmio $\left(\mathrm{Cd}^{2+}\right)$ e zinco $\left(\mathrm{Zn}^{2+}\right)$ são precipitados na zona de superfície do composto hidratado, enquanto o cromo $\left(\mathrm{Cr}^{3+}\right)$ pode ser incorporado no interior do composto, especialmente no interior do silicato de cálcio hidratado (C-S-H), que apresenta a fórmula molecular $\mathrm{CaO} \cdot 2 \mathrm{SiO}_{2} \cdot 3 \mathrm{H}_{2} \mathrm{O}$ (CONNER, 1990).

Os íons cádmio $\left(\mathrm{Cd}^{2+}\right)$ e zinco $\left(\mathrm{Zn}^{2+}\right)$ foram precipitados na matriz, reagindo com a portlandita $-\mathrm{Ca}(\mathrm{OH})_{2}$, resultando na substituição dos íons $\mathrm{Cd}^{2+}$ e $\mathrm{Zn}^{2+}$ e gerando um duplo composto de $\mathrm{CdCa}(\mathrm{OH})_{4} \mathrm{e}$ $\mathrm{CaZn}_{2}(\mathrm{OH})_{5} \cdot 2 \mathrm{H}_{2} \mathrm{O}$.

Segundo Conner (1990), quando se utiliza cimento Portland comum (CPC) para E/S resíduos sólidos industriais perigosos, o pH da matriz favorece a conversão de cátions em hidróxidos, óxido e carbonatos insolúveis, incorporando íons metálicos à estrutura cristalina da matriz de cimento. O óxido de mercúrio e os sais de bário permanecem na superfície da partícula de cimento, pois, com a elevação do $\mathrm{pH}$, os cátions de bário $\left(\mathrm{Ba}^{2+}\right)$ e mercúrio $\left(\mathrm{Hg}^{2+}\right)$ são convertidos para a forma de óxido $(\mathrm{HgO})$ e carbonatos insolúveis $\left(\mathrm{BaSO}_{4}\right.$ e $\left.\mathrm{BaCO}_{3}\right)$.

Dois aspectos são importantes para o entendimento da E/S. O primeiro está relacionado ao critério de imobilização dos contaminantes. Fica evidenciado que os contaminantes são aprisionados ou retidos na forma de um precipitado na superfície da matriz e/ou são incorporados em seu interior. O segundo aspecto está relacionado ao critério de integridade/durabilidade dos materiais, principalmente quando se afirma que a matriz E/S aprisiona ou retém os contaminantes por meio de mecanismos físicos, sem ocorrerem necessariamente reações químicas, mas aprisionamento físico (BRITO, 2007; SPENCE; SHI, 2005). 
A E/S pode ser entendida como duas etapas que se completam e ocorrem no momento em que os agentes aglomerantes entram em contato com os contaminantes: uma denominada solidificação, que visa encapsular o resíduo, formando um material sólido, o qual não necessariamente envolve interação química entre contaminantes e aglomerantes; e outra denominada estabilização, que confere aos elementos poluentes alteração das características perigosas, fixando os mesmos na matriz e reduzindo sua migração para o meio ambiente (BRITO, 2007)

Chen et al (2005), Shawabkeh (2005) e Zhang et al (2007) realizaram a E/S de resíduos perigosos contendo chumbo, cádmio e zinco. Em todos os trabalhos, os autores conseguiram reduzir a concentração desses metais diminuindo a capacidade tóxica e o efeito negativo ao meio ambiente.

Para os propósitos deste trabalho, a E/S busca limitar a lixiviação e a solubilidade, diminuindo a superfície de exposição dos contaminantes, em caso de contato com um fluido lixiviante. O fluido lixiviante é obtido na preparação do ensaio de lixiviação e solubilização. Na lixiviação e na solubilização, ocorre o contato entre a matriz sólida e o solvente, dando lugar a uma transferência de matéria, ou seja, transferência de contaminante para o meio externo.

Nesse sentido, o trabalho teve como objetivo avaliar materiais estabilizados por solidificação por meio de critérios de integridade/ durabilidade e imobilização dos contaminantes, avaliando o comportamento dos critérios frente ao material E/S.

\section{Metodologia}

O trabalho foi dividido nas seguintes etapas: i) planejamento experimental; ii) realização da E/S de resíduo sintético (RS) contendo metais pesados e iii) avaliação dos materiais obtidos por meio de ensaios de integridade/durabilidade e imobilização dos contaminantes pela aplicação do protocolo de avaliação proposto por Brito (2007).

\section{Planejamento experimental}

Foram realizados experimentos visando comparar o desempenho de diferentes matrizes E/S. Para tanto, foram feitos planejamentos experimentais para avaliar e comparar o desempenho de quatro matrizes, constituídas de diferentes misturas. Foi adotado o planejamento completamente aleatorizado com um único fator, ou seja, foram comparadas as médias dos quatro tratamentos entre si e em relação aos limites para cada ensaio.

Foram realizadas três repetições para cada um dos quatro tratamentos, para os quais foi usada água deionizada e isenta de orgânicos. Os tratamentos estão apresentados na Tabela 1.

Na Tabela 1, constata-se que o objetivo foi usar uma relação líquido/sólido (L/S) próxima de 0,50 para que as propriedades dos corpos de prova fossem padronizadas, conforme recomendação de Silva (1998), que utilizou uma relação L/S entre 0,500 e 0,530 para o tratamento de escória de alto-forno com argamassas de cimento. Os corpos de prova foram preparados seguindo basicamente as etapas apresentadas na Figura 2

A Figura 3 mostra os corpos de provas A, B, C e D após a desmoldagem e aptos à avaliação.

Com relação aos corpos de prova apresentados na Figura 3, podem-se fazer as seguintes considerações: i) após período de 24 horas, os corpos de prova foram retirados do interior do molde e deixados por um período de 28 dias; ii) a temperatura do ambiente e a umidade relativa foram controladas em valores próximos a $24 \pm 4^{\circ} \mathrm{C}$ e 50 a $100 \%$ respectivamente e iii) foram realizados ensaios referentes aos ensaios de integridade/durabilidade e imobilização dos contaminantes (BRITO, 2007).

Neste trabalho, as matrizes foram avaliadas comparando os valores obtidos de cada tratamento com os limites máximos permissíveis, conforme NBR 10.004 (ASSOCIAÇÃO BRASILEIRA DE NORMAS TÉCNICAS, 2004C).

Tabela 1 - Tratamentos A, B, C e D com as massas e os valores percentuais do aglomerante, resíduo sintético e volume de água

\begin{tabular}{|c|c|c|c|c|c|c|c|c|}
\hline \multirow{2}{*}{ Tratamento } & \multirow{2}{*}{$\begin{array}{c}\text { Aglomerante } \\
\text { (\%) }\end{array}$} & \multirow{2}{*}{$\begin{array}{c}\text { Resíduo } \\
\text { sintético (\%) }\end{array}$} & \multirow{2}{*}{$\begin{array}{l}\text { Água } \\
(\mathrm{mL})\end{array}$} & \multicolumn{3}{|c|}{ Massa aglomerante (g) } & \multirow{2}{*}{$\begin{array}{l}\text { Massa do } \\
\text { resíduo } \\
\text { sintético }(\mathrm{g})\end{array}$} & \multirow{2}{*}{$\begin{array}{r}\text { Massa } \\
\text { final }(g)\end{array}$} \\
\hline & & & & $\mathrm{CPC}^{\mathrm{a}}$ & Bentonita $^{b}$ & $\mathrm{Cal}^{\mathrm{c}}$ & & \\
\hline \multirow[t]{2}{*}{ A } & 100 & 0 & 75,000 & 105,001 & 7,500 & 37,500 & 0,000 & 225,001 \\
\hline & & & & & $(m=150,000$ & & & \\
\hline \multirow[t]{2}{*}{ B } & 60 & 40 & 75,173 & 63,145 & 4,510 & 22,552 & 60,138 & 225,518 \\
\hline & & & & & $(m=90,207)$ & & & \\
\hline \multirow[t]{2}{*}{ C } & 50 & 50 & 75,143 & 52,600 & 3,757 & 18,786 & 75,143 & 225,429 \\
\hline & & & & & $(m=75,143)$ & & & \\
\hline \multirow[t]{2}{*}{ D } & 40 & 60 & 75,092 & 42,051 & 3,004 & 15,018 & 90,110 & 225,275 \\
\hline & & & & & $(m=60,073)$ & & & \\
\hline
\end{tabular}

Fonte: Brito (2007)

a CPC: cimento Portland comum - 70\% em relação a $150 \mathrm{~g}, 90,207 \mathrm{~g}, 75,143 \mathrm{~g}$ e $60,073 \mathrm{~g}$ respectivamente para os tratamentos $\mathrm{A}, \mathrm{B}, \mathrm{C}$ e $\mathrm{D}$; b bentonita sódica - $5 \%$ em relação a $150 \mathrm{~g}$, 90,207 g, 75,143 g e 60,073 g respectivamente para os tratamentos A, B, C e D; ' hidróxido de cálcio - Cal - 25\% em relação a 150 g, 90,207 g, 75,143 g e 60,073 g respectivamente para os tratamentos A, B, C e D. 


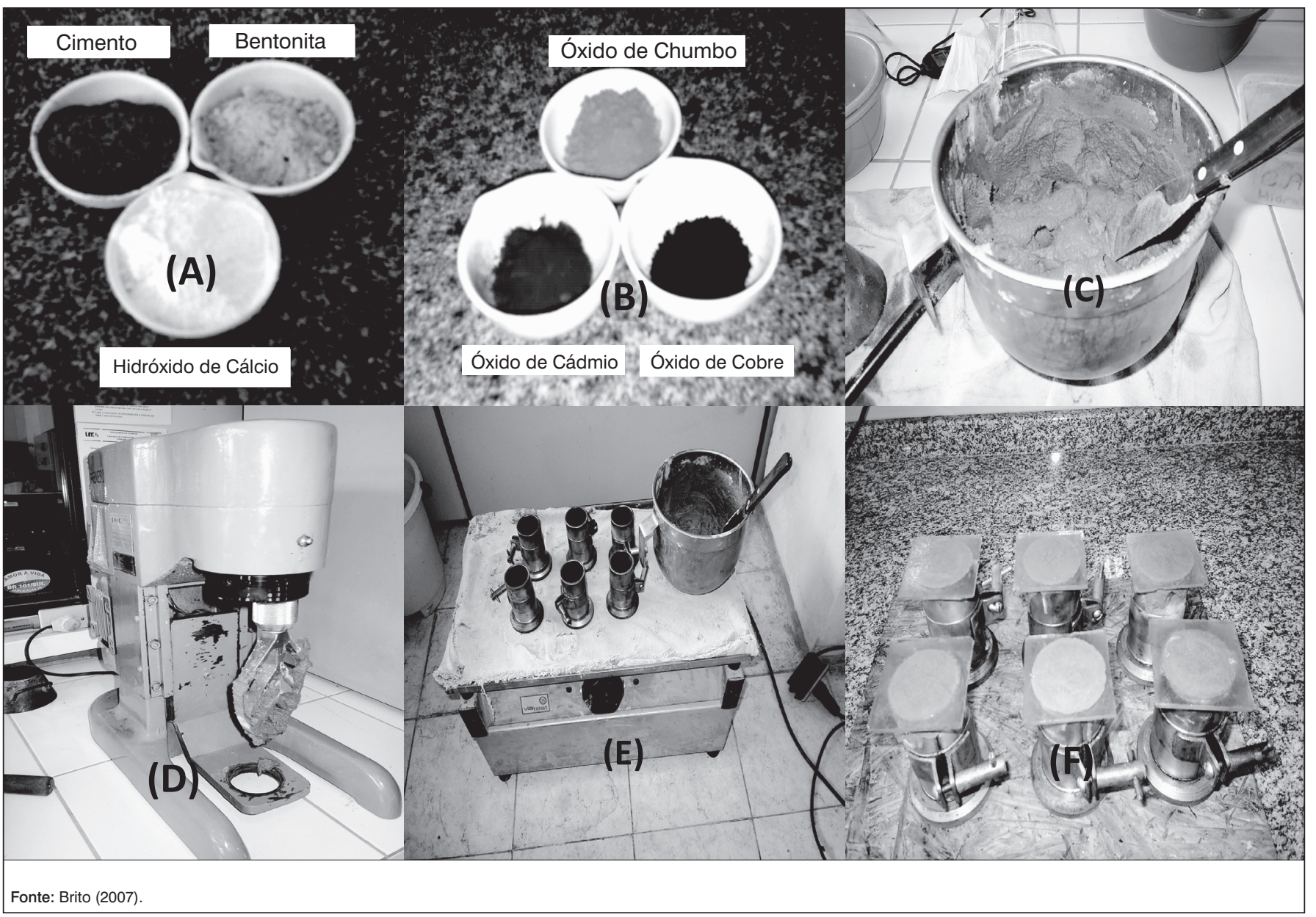

Figura 2 - Sequência de preparação dos corpos de prova: (A) aglomerantes, (B) contaminantes, (C) mistura entre aglomerantes e contaminantes, (D) homogeneização da mistura, $(E)$ enchimento dos corpos de prova e $(F)$ moldagem dos corpos de prova

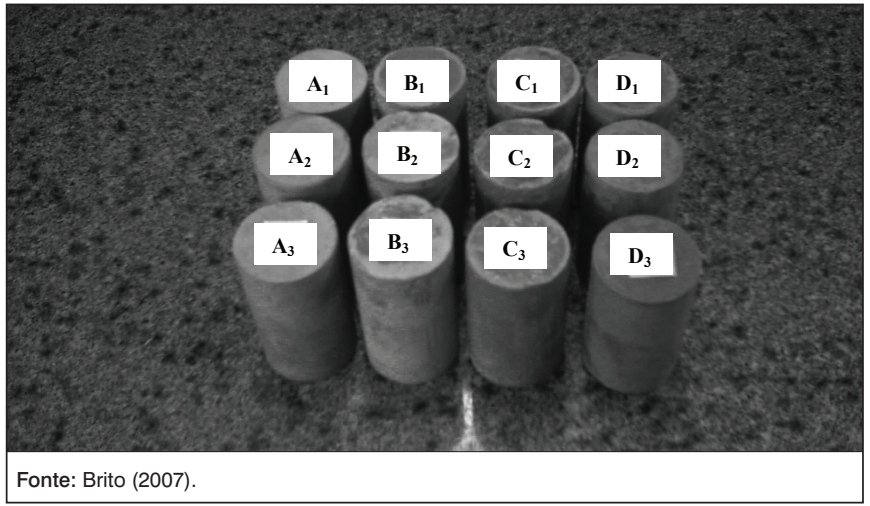

Figura 3 - Corpos de prova após a estabilização por solidificação com os tratamentos A, B, C e D aptos à avaliação

A análise de variância (ANOVA) foi utilizada para decidir, com certo nível de confiança, se os tratamentos são significativamente iguais ou diferentes entre si, em relação aos critérios de integridade/ durabilidade e imobilização dos contaminantes (MONTGOMERY; RUNGER, 2003).

A Tabela 2 apresenta a ANOVA para comparar os quatro tratamentos (A, B, C e D), com o seguinte critério de decisão:
- se o valor $\mathrm{p}$ for $\leq 0,01$ ou 0,05, indica-se que as médias dos tratamentos são significativamente diferentes;

- se o valor $\mathrm{p}$ for >0,01 ou 0,05, indica-se que as médias dos tratamentos não são significativamente diferentes.

A Tabela 2 mostra também que é possível encontrar um valor p (menor nível de significância que conduz a rejeitar a hipótese de que as médias são iguais a partir de um conjunto de dados) para a estatística de teste, conforme critério de decisão apresentado anteriormente.

\section{Avaliação dos materiais E/S}

Os materiais foram avaliados por meio de ensaios de integridade/ durabilidade e por ensaios relacionados com a imobilização dos contaminantes, aplicando o protocolo de avaliação de materiais estabilizados por solidificação.

A Figura 4 mostra o fluxograma de avaliação de materiais E/S de resíduos. O fluxograma apresentado na Figura 4 é baseado no protocolo de avaliação de materiais E/S proposto por Brito (2007). 
Tabela 2 - ANOVA dos experimentos para comparar o efeito dos quatro tratamentos: A, B, C e D

\begin{tabular}{lcccc} 
Fonte da variação & Graus de liberdade & Soma de quadrado & Quadrado médio & Valor $p$ \\
Tratamento & $\mathrm{k}-1$ & $\mathrm{SQ}_{\text {Tratamento }}$ & $\mathrm{QM}_{\text {Tratamento }}$ & $\mathrm{QM}_{\text {Residuo }}$ \\
Residual & $\mathrm{n}-\mathrm{k}$ & $\mathrm{SQ}_{\text {Residuo }}$ & ${ }^{* *} \mathrm{OU}^{*}$ \\
Total & $\mathrm{n}-1$ & $\mathrm{SQ}_{\text {Total }}$ & - \\
\hline
\end{tabular}

Fonte: Montgomery e Runger (2003).

** significativo ao nível de $1 \%$ de probabilidade; * significativo ao nível de $5 \%$ de probabilidade; $\mathrm{k}=\mathrm{n}^{\circ}$ de tratamentos; $\mathrm{n}=$ número de observação.

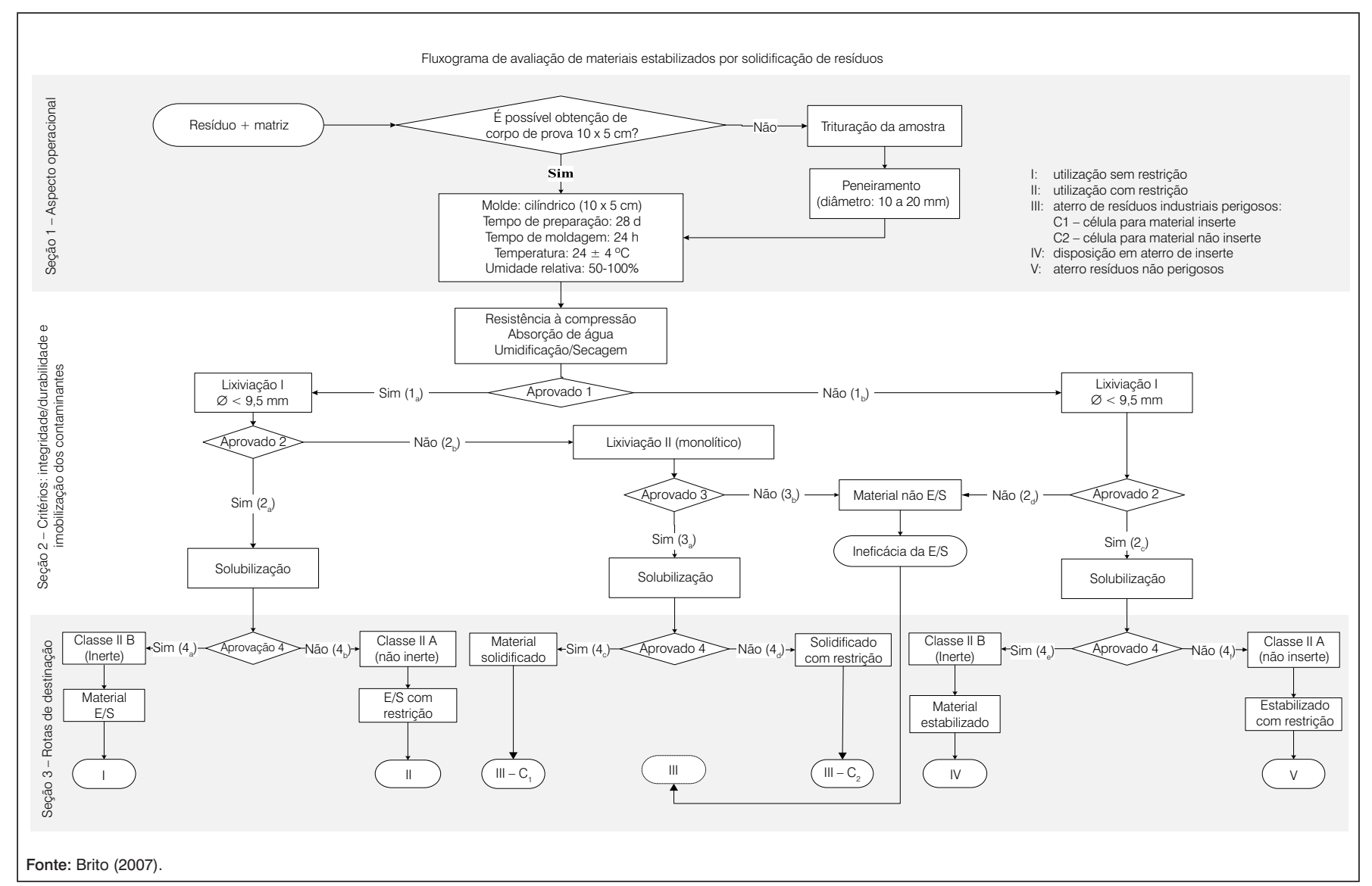

Figura 4 - Fluxograma usado para avaliação de materiais resultantes do processo de E/S

\section{Ensaios de integridade/durabilidade}

Os ensaios de integridade/durabilidade foram: resistência à compressão, absorção de água e umidificação e secagem.

O ensaio de resistência à compressão é usado para verificar a capacidade do material E/S em resistir a diferentes cargas de compressão mecânica, antes e depois da imersão do material em água. A resistência à compressão, portanto, é importante para avaliar a integridade do material E/S. O ensaio de resistência à compressão utilizado foi baseado na NBR 7.215 (ASSOCIAÇÃO BRASILEIRA DE NORMAS TÉCNICAS, 1997).

No ensaio de resistência à compressão são utilizados corpos de prova cilíndricos de $50 \mathrm{~mm}$ de diâmetro e $100 \mathrm{~mm}$ de altura (BRITO, 2007), em que os mesmos são postos diretamente sobre o prato inferior de uma prensa, de maneira que fique rigorosamente centrado em relação ao eixo de carregamento. A velocidade de carregamento da máquina de ensaio, ao transmitir a carga de compressão ao corpo de prova, deve ser equivalente a 0,25 $\pm 0,05 \mathrm{MPa} / \mathrm{s}$.

O ensaio de absorção de água foi realizado conforme NBR 9.778 (ASSOCIAÇÃO BRASILEIRA DE NORMAS TÉCNICAS, 1987). O ensaio recomenda que se deva trabalhar com corpos de prova condicionados em estufa a $103 \pm 2{ }^{\circ} \mathrm{C}$ e com uma relação L/S 10:1, utilizando água desmineralizada com resistividade maior que $0,2 \mathrm{M} \Omega . \mathrm{cm}$.

No ensaio de absorção de água após pesagem das amostras, elas devem ser enviadas para estufa a $103^{\circ} \mathrm{C}$ por 24 horas. Posteriormente, as amostras devem ser imersas em água a $23^{\circ} \mathrm{C}$ por períodos de 24 , 48 e 72 horas. O resultado é expresso em \%, conhecendo-se a massa do corpo de prova após saturação em água e a massa do corpo de prova seca em estufa. 
O ensaio de umidificação/secagem foi realizado com base no procedimento recomendado pelo Wastewater Technology Center (WASTEWATER TECHNOLOGY CENTER, 1991). Neste ensaio, a amostra foi submetida a seis ciclos de umidificação com água a $22 \pm$ $2{ }^{\circ} \mathrm{C}$, secagem em estufa sob temperatura de $105 \pm 5^{\circ} \mathrm{C}$ e umidificação por 24 horas.

\section{Ensaios de imobilização dos contaminantes}

Para a avaliação da imobilização dos contaminantes, foram empregados os ensaios de lixiviação e solubilização, propostos respectivamente pela NBR 10.005 e 10.006 (ASSOCIAÇÃO BRASILEIRA DE NORMAS TÉCNICAS, 2004B, 2004C).

No ensaio de lixiviação, uma amostra representativa de $100 \mathrm{~g}$ (base seca) foi colocada em frasco de $2.000 \mathrm{~mL}$ com água deionizada e isenta de matéria orgânica mais solução lixiviante (ácido acético glacial e água). Em seguida, a solução foi submetida à agitação em equipamento rotativo com 30 rotações por minuto, relação L/S igual a 20:1 e tempo de contato com o meio lixiviante igual a $18 \pm 2$ horas

Neste trabalho, o ensaio de lixiviação foi realizado com a amostra triturada (lixiviação I) e com amostra na forma monolítica, ou seja, sem trituração (lixiviação II), conforme protocolo de avaliação de materiais E/S (BRITO, 2007).

Para o ensaio de lixiviação I, as amostras foram aquelas preparadas em moldes com dimensões de $5 \mathrm{~cm}$ de diâmetro e $10 \mathrm{~cm}$ de altura. Para o ensaio de lixiviação II, que é uma adaptação dos ensaios da NBR 10.005 (ASSOCIAÇÃO BRASILEIRA DE NORMAS TÉCNICAS, 2004B) e da TCLP 1311 (UNITED STATE ENVIRONMENTAL PROTECTION AGENCY, 1992), o corpo de prova não foi triturado, ou seja, foi utilizado o corpo de prova na forma de um sólido monolítico com massa igual a $100 \mathrm{~g}$.

O ensaio de solubilização se caracteriza por usar amostra triturada, uma relação L/S igual a 4:1 e repouso de sete dias em temperatura ambiente. No ensaio de solubilização, uma amostra representativa de $250 \mathrm{~g}$ (base seca) do material foi colocada em frasco de $1.500 \mathrm{~mL}$. Em seguida, foram adicionados $1.000 \mathrm{~mL}$ de água deionizada e isenta de orgânicos. Os metais foram quantificados após repouso por sete dias, em temperatura de $25^{\circ} \mathrm{C}$.

Neste trabalho, para determinar a concentração dos contaminantes no extrato lixiviado e no líquido solubilizado, foi utilizada a técnica de espectroscopia de absorção atômica (AAS).

\section{Cálculo da concentração dos contaminantes}

A concentração do extrato lixiviado e do solubilizado foi apresentada em mg. $\mathrm{kg}^{-1}$, considerando e desconsiderando a diluição dos contaminantes. Para o cálculo da concentração em mg. $\mathrm{kg}^{-1}$ dos contaminantes considerando a diluição dos metais pesados na massa do resíduo, foi tomado como base o resultado em mg. $\mathrm{L}^{-1}$. Neste caso, o resultado em mg. $\mathrm{kg}^{-1}$ é obtido a partir da concentração do contaminante em mg. $\mathrm{L}^{-1}$ e sua relação com o volume da solução lixiviante usada no ensaio de lixiviação ou solubilização e a massa da amostra $\left(\mathrm{L} . k g^{-1}\right)$. Por exemplo, para fazer a transformação de mg. $\mathrm{L}^{-1}$ para mg. $\mathrm{kg}^{-1}$, usou-se a Equação 1:

$\left[\mathrm{mg} \cdot \mathrm{kg}^{-1}\right]=\mathrm{mg} \cdot \mathrm{L}^{-1} \mathrm{xL} \cdot \mathrm{kg}^{-1}$

Equação 1

onde:

[mg. $\left.\mathrm{kg}^{-1}\right]$ : concentração em mg. $\mathrm{kg}^{-1}$ do extrato lixiviado ou solubilizado, considerando a diluição dos contaminantes;

[mg. $\left.\mathrm{L}^{-1}\right]$ : concentração em mg. $\mathrm{L}^{-1}$ do extrato lixiviado ou solubilizado;

[L.kg-1]: relação entre volume do extrato lixiviado ou solubilizado e a massa da amostra usada no ensaio de lixiviação ou solubilização.

Na Equação 1, a massa da amostra $\left(m_{\text {amostra }}\right)$ é aquela do ensaio de lixiviação $(0,100 \mathrm{~kg})$ ou solubilização $(0,250 \mathrm{~kg})$.

Para evitar o que muitos autores têm realizado para apresentar a concentração dos contaminantes foi empregada a Equação 2, utilizada para calcular a concentração dos contaminantes desconsiderando a diluição do resíduo no aglomerante, pois, segundo Andrés et al (1998), muitos trabalhos demonstram que a eficiência de processo de E/S não passa na verdade de uma simples diluição. Neste trabalho, será usada a Equação 2 para cálculos dos contaminantes (BRITO, 2007).

Portanto, a determinação da concentração dos contaminantes, desconsiderando a diluição dos metais pesados (contaminantes) no aglomerante, foi realizada por meio da Equação 2. Após determinação da concentração do lixiviado e do solubilizado, foi utilizada a Equação 2, que se caracteriza por determinar a concentração do contaminante em função: (i) da concentração do ensaio de lixiviação/solubilização em mg. $\mathrm{kg}^{-1}$, desconsiderando a diluição dos contaminantes; (ii) da massa da amostra usada no ensaio de lixiviação ou solubilização em kg; e (iii) da massa do resíduo sólido industrial em $\mathrm{kg}$

$[\mathrm{X}]=\frac{\left[\mathrm{mg} \cdot \mathrm{kg}^{-1}\right]_{\mathrm{x}} \cdot \mathrm{m}_{\text {amostra (lix/sol) }}}{\mathrm{m}_{\text {Residuo }}}$

Equação 2

onde:

[x]: concentração do lixiviado/solubilizado desconsiderando a diluição do resíduo no aglomerante $\left(\mathrm{mg} \cdot \mathrm{kg}^{-1}\right)$;

[mg. $\left.\mathrm{kg}^{-1}\right]$ : concentração do extrato lixiviado ou solubilizado (mg. $\left.\mathrm{kg}^{-1}\right)$; $\mathrm{m}_{\text {amostra (lix/sol) }}$ : massa da amostra no ensaio de lixiviação/solubilização $(\mathrm{kg})$;

$\mathrm{m}_{\text {Residuo }}$ : massa do resíduo $(\mathrm{kg})$. 


\section{Resultados}

Na Tabela 3, estão apresentados os resultados médios dos tratamentos A, B, C e D em função da avaliação dos materiais estabilizados e solidificados, em que a retenção dos contaminantes foi verificada por meio dos critérios de integridade e durabilidade e imobilização dos contaminantes. A concentração do material bruto para o RS em $\mathrm{mg} \cdot \mathrm{kg}^{-1}$ foi bastante elevada, indicando que ele continha significativo teor de contaminantes (125,878 mg. $\mathrm{kg}^{-1}$ para o cádmio; 92,875 mg.kg-1 para o chumbo e 79,451 mg.kg-1 para o cobre).

Os resultados da Tabela 4 mostram que houve diferença significativa para os ensaios de resistência à compressão, absorção de água, umidificação e secagem, solubilização (cádmio e chumbo) e lixiviação ao nível de $1 \%$ de probabilidade, pois, o valor de $\mathrm{p}$ foi $<0,01$.

O material foi avaliado aplicando-se o protocolo de avaliação de materiais estabilizados por solidificação proposto por Brito (2007), conforme Figura 4.

A Tabela 5 mostra os limites máximos permissíveis para os critérios de integridade e durabilidade para avaliar material E/S.

A Tabela 6 mostra resumidamente os valores máximos permissíveis para avaliar o critério de imobilização dos contaminantes do material E/S, em que a mesma é importante por considerar a avaliação do resíduo em $\mathrm{mg} \cdot \mathrm{kg}^{-1}$. Os valores de referência para os limites máximos permissíveis para o critério de integridade/durabilidade e imobilização dos contaminantes estão publicados no trabalho de Brito (2007). Para a resistência à compressão, os valores máximos permissíveis são baseados no trabalho de Mulder (2002), Journal Officiel de La République Française (1994) e o Protocolo do Canadá conforme Stegemann e Côté (1991). Para a capacidade de absorção, os valores foram baseados na recomendação de Spence e Shi (2005) e da NBR 9.778 (1987). Para a umidificação e secagem, os limites máximos foram baseados na recomendação da Agência Francesa de Normalização (AGENCE FRANÇAISE DE NORMALISATION, 1994).

\section{Discussão}

$\mathrm{Na}$ Tabela 3, o ensaio de lixiviação I se caracteriza por utilizar partículas $<9,5 \mathrm{~mm}$ e a lixiviação II se caracteriza por utilizar amostra no formato monolítico. A técnica usada foi a AAS. A partir dos resultados médios apresentados na Tabela 3, foi realizada a ANOVA e interpretada por meio do valor de p.

A concentração dos materiais tratados (A, B, C e D) apresentados nessa tabela, em termos de lixiviação, se apresentou reduzida, quando comparada à concentração do material bruto.

A concentração dos contaminantes, quando se usa a Equação 2 (desconsidera a diluição dos metais pesados ou contaminantes no aglomerante), é sempre maior quando a equação não é utilizada. Neste caso, com a utilização da Equação 2, os resultados da concentração realmente avaliam o material de forma correta, evitando
Tabela 3 - Resultados médios para os tratamentos A, B, C, D dos ensaios de integridade e durabilidade e imobilização dos contaminantes

\begin{tabular}{|c|c|c|c|c|}
\hline $\begin{array}{l}\text { Critério de integridade/ } \\
\text { durabilidade }\end{array}$ & $\mathrm{A}(0 \%)$ & B (40\%) & C (50\%) & D (60\%) \\
\hline $\begin{array}{l}\text { Resistência à compressão } \\
\text { (MPa) - antes da imersão } \\
\text { em água }\end{array}$ & 6,563 & 3,096 & 4,180 & 4,470 \\
\hline $\begin{array}{l}\text { Resistência à compressão } \\
\text { (MPa) - após imersão em } \\
\text { água }\end{array}$ & 1,380 & 0,681 & 0,919 & 0,983 \\
\hline Absorção de água (\%) & 37,061 & 50,061 & 36,852 & 38,583 \\
\hline Umidificação/secagem (\%) & 10,814 & 11,457 & 11,951 & 10,345 \\
\hline $\begin{array}{l}\text { Critério de imobilização dos } \\
\text { contaminantes }\end{array}$ & A & B & C & D \\
\hline Lixiviação I - $\mathrm{Cd}^{2+}\left(\mathrm{mg} \cdot \mathrm{kg}^{-1}\right)$ & ND & $\begin{array}{l}3,784^{1} \\
6,307^{2}\end{array}$ & $\begin{array}{c}8,541^{1} \\
11,387^{2}\end{array}$ & $\begin{array}{l}29,485^{1} \\
32,814^{2}\end{array}$ \\
\hline Lixiviação I - $\mathrm{Pb}^{2+}\left(\mathrm{mg} \cdot \mathrm{kg}^{-1}\right)$ & ND & $\begin{array}{l}4,998^{1} \\
8,330^{2}\end{array}$ & $\begin{array}{l}14,885^{1} \\
19,846^{2}\end{array}$ & $\begin{array}{l}26,748^{1} \\
29,768^{2}\end{array}$ \\
\hline Lixiviação I - $\mathrm{Cu}^{3+}\left(\mathrm{mg} \cdot \mathrm{kg}^{-1}\right)$ & ND & $\begin{array}{c}8,321^{1} \\
13,868^{2}\end{array}$ & $\begin{array}{l}15,850^{1} \\
21,132^{2}\end{array}$ & $\begin{array}{l}22,090^{1} \\
24,584^{2}\end{array}$ \\
\hline Solubilização - Cd ${ }^{2+}\left(\mathrm{mg} \cdot \mathrm{kg}^{-1}\right)$ & ND & $\begin{array}{l}0,014^{1} \\
0,058^{2}\end{array}$ & $\begin{array}{l}0,027^{1} \\
0,093^{2}\end{array}$ & $\begin{array}{l}0,054^{1} \\
0,151^{2}\end{array}$ \\
\hline Solubilização - $\mathrm{Pb}^{2+}\left(\mathrm{mg} \cdot \mathrm{kg}^{-1}\right)$ & ND & $\begin{array}{l}0,300^{1} \\
1,252^{2}\end{array}$ & $\begin{array}{l}0,600^{1} \\
2,004^{2}\end{array}$ & $\begin{array}{l}1,000^{1} \\
2,785^{2}\end{array}$ \\
\hline Solubilização - $\mathrm{Cu}^{2+}\left(\mathrm{mg} \cdot \mathrm{kg}^{-1}\right)$ & ND & $\begin{array}{l}0,060^{1} \\
0,250^{2}\end{array}$ & $\begin{array}{l}0,120^{1} \\
0,401^{2}\end{array}$ & $\begin{array}{l}0,180^{1} \\
0,501^{2}\end{array}$ \\
\hline Lixiviação II - $\mathrm{Cd}^{2+}\left(\mathrm{mg} \mathrm{kg}^{-1}\right)$ & - & - & $\begin{array}{l}1,358^{1} \\
2,142^{2}\end{array}$ & $\begin{array}{l}1,980^{1} \\
3,785^{2}\end{array}$ \\
\hline Lixiviação II - $\mathrm{Pb}^{2+}\left(\mathrm{mg} \mathrm{kg}^{-1}\right)$ & - & - & $\begin{array}{l}2,980^{1} \\
3,928^{2}\end{array}$ & $\begin{array}{l}3,452^{1} \\
7,871^{2}\end{array}$ \\
\hline Lixiviação II - Cu+2+ $\left(\mathrm{mg}^{2} \mathrm{~kg}^{-1}\right)$ & - & - & $\begin{array}{l}3,389^{1} \\
5,859^{2}\end{array}$ & $\begin{array}{c}5,338^{1} \\
11,842^{2}\end{array}$ \\
\hline
\end{tabular}

Fonte: Brito (2007).

${ }^{1}$ valor considerando a diluição do resíduo no aglomerante; ${ }^{2}$ valor desconsiderando a diluição do resíduo no aglomerante, conforme Equação 2; ND: não detectado (abaixo do limite de detecção da curva analítica do AAS: $0,010 \mathrm{mg} \cdot \mathrm{kg}^{-1}$ para o cádmio; $0,015 \mathrm{mg} \cdot \mathrm{kg}^{-1}$ para o chumbo e $0,010 \mathrm{mg}^{\mathrm{kg}}{ }^{-1}$ para o cobre.

Tabela 4 - Resultado da ANOVA para os valores de p para os ensaios realizados

\begin{tabular}{lc} 
Critério de integridade/durabilidade & Valor de p \\
$\begin{array}{l}\text { Resistência à compressão (antes imersão) } \\
\text { e absorção de água }\end{array}$ & $0,000^{\star *}$ \\
Umidificação/secagem & $0,003^{\star *}$ \\
Lixiviação - cobre, cádmio e chumbo & $0,000^{* *}$ \\
Solubilização - cádmio e chumbo & $0,000^{* *}$ \\
Solubilização - cobre & $0,019^{*}$ \\
\hline
\end{tabular}

Fonte: Brito (2007)

* significativo ao nível de $5 \%$ de probabilidade (valor $p \leq 0,05$ ); ** significativo ao nível de $1 \%$ de probabilidade (valor $\mathrm{p} \leq 0,01)$.

que a avaliação seja em função da diluição do contaminante no aglomerante.

\section{Análise estatística e rotas de destinação do material $\mathrm{E} / \mathrm{S}$}

Com exceção do ensaio de solubilização para o contaminante cobre, a diferença foi significativa ao nível de 5\% de probabilidade. Estes 
resultados mostram que o percentual do contaminante influenciou nas características dos quatro tratamentos (Tabela 4).

Aplicando o protocolo de avaliação de materiais estabilizados por solidificação (Figura 4), observou-se que o material A foi aprovado no critério de integridade/durabilidade $\left(1_{\mathrm{a}}\right)$ e imobilização dos con-

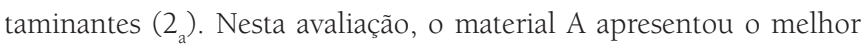
desempenho, pois foi aprovado em todos os ensaios referentes aos critérios de avaliação.

A composição deste material pode ser aplicada em diversos usos, como aditivo na fabricação de tijolos, blocos vazados, reboco de parede e material de base de cobertura em obras de pavimentação, dependendo apenas da composição necessária para aplicação de cada material (MULDER, 2002; SPENCE, SHI, 2005).

O material B não foi aprovado no critério de integridade/durabilidade $\left(1_{b}\right)$, sendo reprovado no ensaio de absorção de água, seguindo para a rota de destinação IV (disposição em aterro de inerte) ou
$\mathrm{V}$ (aterro de resíduos não perigosos). Ressalta-se ainda que, apesar da amostra ser aprovada nos ensaios de resistência à compressão e umidificação/secagem, o protocolo de avaliação considera a amostra aprovada em determinado critério quando ela for aprovada em todos os ensaios daquele critério.

Por outro lado, o material B foi aprovado também no ensaio de lixiviação I $\left(2_{c}\right)$ e reprovado no ensaio de solubilização $\left(4_{f}\right)$, sendo considerado um material estabilizado com restrição. Neste caso, é recomendada a disposição do material em aterro de resíduo não perigoso, seguindo para a rota $\mathrm{V}$ (aterro de resíduos não perigosos).

$\mathrm{Na}$ avaliação do material C, ele foi aprovado em todos os ensaios relacionados à integridade/durabilidade $\left(1_{a}\right)$, ou seja, no ensaio de absorção de água, umidificação e secagem e resistência à compressão. Em relação aos ensaios do critério de imobilização dos contaminantes, o material C foi reprovado no ensaio de lixiviação I ( $2_{a}$ ), pois o valor de cádmio estava acima do recomendado. Nesta situação, o material

Tabela 5 - Limites máximos permissíveis para os critérios de integridade/durabilidade para avaliar matérias estabilizadas por solidificação

\begin{tabular}{|c|c|c|c|c|c|}
\hline Integridade e durabilidade & Material E/S & $\begin{array}{c}\text { Material E/S } \\
\text { com restrição }\end{array}$ & $\begin{array}{c}\text { Material } \\
\text { solidificado }\end{array}$ & $\begin{array}{c}\text { Material } \\
\text { estabilizado }\end{array}$ & $\begin{array}{l}\text { Estabilizado } \\
\text { restrição }\end{array}$ \\
\hline & (l) & (II) & (III) & (IV) & (V) \\
\hline $\begin{array}{l}\text { Resistência à compressão } \\
\text { (antes imersão: água)a }^{\text {(após imersão: água) }^{\mathrm{b}}}\end{array}$ & $\begin{array}{c}\geq 1 \mathrm{MPa} \\
\geq 0,35 \mathrm{MPa}\end{array}$ & $\begin{array}{c}\geq 1 \mathrm{MPa} \\
\geq 0,35 \mathrm{MPa}\end{array}$ & $\begin{array}{l}\geq 0,8 \mathrm{Mpa} \\
\geq 0,5 \mathrm{Mpa}\end{array}$ & $\begin{aligned} & <1 \mathrm{MPa} \\
< & 0,35 \mathrm{MPa}\end{aligned}$ & $\begin{aligned} & <1 \mathrm{MPa} \\
< & 0,35 \mathrm{MPa}\end{aligned}$ \\
\hline Capacidade de absorção de águac & $\leq 40 \%$ & $\leq 40 \%$ & $>40 \%$ & $>40 \%$ & $>40 \%$ \\
\hline Umidificação/secagem: 6 ciclos & Perda peso: $\leq 15 \%$ & Perda peso: $\leq 15 \%$ & Perda peso: $>15 \%$ & Perda peso: $>15 \%$ & Perda peso: $>15 \%$ \\
\hline
\end{tabular}

Fonte: Brito (2007).

a parâmetros e limites máximos no extrato lixiviado e solubilizado, conforme recomendação da NBR 10.005 (2004A) e 10.006 (2004B) e Usepa, 1992; b valores baseados no Ministério da Saúde (MS), Portaria n. 518 de 2004 (BRASIL, 2004); ' valores sugeridos pela Companhia de Tecnologia de Saneamento Ambiental (2005), Portaria n. 195 de 2005; I: utilização sem restrição: II: armazenagem resíduos não inertes; III: aterro de resíduos perigosos; IV: utilização controlada; V: aterro de resíduos não perigosos.

Tabela 6 - Limites máximos permissíveis para avaliar o critério de imobilização dos contaminantes nos ensaios de lixiviação e solubilização

\begin{tabular}{|c|c|c|c|c|}
\hline \multirow{2}{*}{ Parâmetro (contaminantes) } & \multicolumn{2}{|c|}{ Lixiviação } & \multicolumn{2}{|c|}{ Solubilização } \\
\hline & $\left(\mathrm{mg} \cdot \mathrm{L}^{-1}\right)$ & $\left(\mathrm{mg} \cdot \mathrm{kg}^{-1}\right)$ & $\left(\mathrm{mg} \cdot \mathrm{L}^{-1}\right)$ & $\left(\mathrm{mg} \cdot \mathrm{kg}^{-1}\right)$ \\
\hline Arsênio ${ }^{a}$ & 1,0 & 20,0 & 0,01 & 0,04 \\
\hline Alumíniob & 0,2 & 4,0 & 0,2 & 0,8 \\
\hline Bárioa & 70,0 & $1.400,0$ & 0,7 & 2,8 \\
\hline Cádmio ${ }^{\mathrm{a}}$ & 0,5 & 10,0 & 0,005 & 0,03 \\
\hline Chumboa & 1,0 & 20,0 & 0,01 & 0,02 \\
\hline Cobre $^{c}$ & 2,0 & 40,0 & 2,0 & 8,0 \\
\hline Cromo totala $^{a}$ & 5,0 & 100,0 & 0,05 & 0,2 \\
\hline Ferro $^{c}$ & 0,3 & 6,0 & 0,3 & 1,2 \\
\hline Fluoreto $^{a}$ & 150,0 & $3.000,0$ & 1,5 & 6,0 \\
\hline Manganês ${ }^{b}$ & 0,1 & 2,0 & 0,1 & 0,4 \\
\hline Mercúrioa & 0,1 & 2,0 & 0,001 & 0,004 \\
\hline Níquel $^{\mathrm{c}}$ & 0,02 & 0,4 & 0,02 & 0,08 \\
\hline Nitrato $^{\mathrm{b}}(\mathrm{N})$ & 10,0 & 200 & 10,0 & 40,0 \\
\hline Nitrito $^{\mathrm{b}}(\mathrm{N})$ & 1,0 & 20,0 & 1,0 & 4,0 \\
\hline Prata $^{a}$ & 5,0 & 25,0 & 0,05 & 0,20 \\
\hline Selênio ${ }^{a}$ & 1,0 & 20,0 & 0,01 & 0,04 \\
\hline Zinco $^{c}$ & 5,0 & 100,0 & 5,0 & 20,0 \\
\hline
\end{tabular}

Fonte: Brito (2007).

a parâmetros e limites máximos no extrato lixiviado e solubilizado, conforme recomendação da NBR 10.005 (2004B) e 10.006 (2004A); b valores baseados no Ministério da Saúde (MS),

Portaria n. 518 de 2004 (BRASIL, 2004); ' valores sugeridos pela Companhia de Tecnologia de Saneamento Ambiental (2005), Portaria n. 195 de 2005. 
foi avaliado por meio do ensaio de lixiviação II, sendo aprovado no mesmo ( $3_{\mathrm{a}}$ ). Finalmente, o material $\mathrm{C}$ foi reprovado no ensaio de solubilização $\left(4_{\mathrm{d}}\right)$, pois o cádmio e o chumbo apresentaram valores acima do recomendado pela legislação. O material C foi considerado material solidificado com restrição e seguiu para a rota III.

O material obtido a partir do material D foi aprovado nos critérios de integridade/durabilidade $\left(1_{\mathrm{a}}\right)$ e reprovado no ensaio de lixiviação I $\left(2_{b}\right)$. Conforme recomenda o protocolo de avaliação, o material D foi submetido ao ensaio de lixiviação II, que se caracteriza por realizar o ensaio na forma monolítica. Nesta opção, o material foi aprovado no ensaio de lixiviação II (3 ${ }_{a}$, seguindo para o ensaio de solubilização. O material foi reprovado no ensaio de solubilização $\left(4_{\mathrm{d}}\right)$, sendo denominado material solidificado com restrição ao uso e disposto em aterro sanitário industrial em célula de material não inerte (rota III).

\section{Conclusões}

Com base nas avaliações realizadas nos materiais estabilizados por solidificação, pode-se concluir que:

1. do ponto de vista técnico, podem ser destacados como vantagem da E/S a disponibilidade e a ocorrência de minerais como matérias-primas para preparação das misturas, e o reduzido custo dos materiais e dos equipamentos para realização do processo;

2. do ponto de vista econômico, a E/S em matrizes de cimento, bentonita e hidróxido de cálcio é considerada vantajosa quando comparada a outras tecnologias disponíveis, sendo que o seu produto final pode, em muitos casos, ser comercializado, diminuindo ainda mais os custos do processo;

3. como desvantagem, pode-se citar a falta de conhecimento dos mecanismos envolvidos em relação à comprovação da eficiência do processo, pois são feitas adições de quantidades consideráveis dos aglomerantes durante o processo, o que gera diluição do resíduo perigoso no aglomerante;

4. com a obtenção dos materiais à base de cimento Portland comum, bentonita sódica e hidróxido de cálcio, a resistência à compressão diminuiu com o aumento da absorção de água, ou seja, os materiais apresentaram menor integridade com o aumento da porosidade;

5. a proporção do resíduo influenciou no resultado de lixiviação do cádmio, chumbo e cobre, pois há uma ordem crescente do valor do lixiviado em função do aumento do teor dos contaminantes adicionados em cada tratamento. A diferença significativa entre todos os materiais indica que a proporção de resíduos em relação ao aglomerante influenciou na concentração para todos os materiais.

\section{Agradecimentos}

Os autores agradecem o apoio financeiro concedido pela Coordenação de Aperfeiçoamento de Pessoal de Ensino Superior (Capes), pela concessão da bolsa de estudo, e ao Programa de PósGraduação em Engenharia Sanitária e Ambiental da Universidade Federal de Santa Catarina (UFSC).

\section{Referências}

AGENCE FRANÇAISE DE NORMALISATION. AFNOR NFX31-211: Déchets - Essai de Lessivage d'un déchet solide initialement massif ou généré par un procédé de solidification. Normalisation Française. Paris, 1994.

ANDRÉS, A. et al. Experimental study of the waste binder anhydrite in the solidification/stabilization process of heavy metal sludges. Journal of Hazardous Materials, v. 57, n. 1-3, p. 155-168, 1998.

ASSOCIAÇÃO BRASILEIRA DE NORMAS TÉCNICAS. NBR 10.004 Norma Brasileira de Resíduos Sólidos - Classificação. CENWin, 2004A. Versão digital.

NBR 10.005. Procedimentos para obtenção de extrato lixiviado de resíduos sólidos. CENWin, 2004B. Versão digital.

NBR 10.006. Procedimentos para obtenção de extrato solubilizado de resíduos sólidos. CENWin, 2004C. Versão digital.

NBR 7.215: Cimento Portland: Determinação da resistência à compressão. Rio de Janeiro, 1997

NBR 9.778: Argamassa e concreto endurecido - Determinação da absorção de água por imersão, índice de vazios e massa específica. Rio de Janeiro, 1987.
BRASIL. Ministério da Saúde. Portaria n. 518, de 25 de março de 2004 Estabelece os procedimentos e responsabilidades relativos ao controle e vigilância da qualidade da água para consumo humano e seu padrão de potabilidade, e dá outras providências. Brasília, DF: Diário Oficial da União; 26 mar 2004, Seção 1, p. 266-270.

BRITO, A.L.F. Protocolo de avaliação de materiais resultantes da estabilização por solidificação de resíduos. 2007. 179 f. Tese (Doutorado em Engenharia Ambiental) - UFSC, Florianópolis, 2007.

CHEN, C.L. et al. Stabilization of $\mathrm{Cu}$ in acid-extracted industrial sludge using a microwave process. Journal of Hazardous Materials, v. 123, n. 1-3, p. 256-261, 2005.

COMPANHIA DE TECNOLOGIA DE SANEAMENTO AMBIENTAL. Valores orientativos para solos e águas subterrâneas do estado de São Paulo. Portaria n. 195, São Paulo, 2005.

CONNER, J.R. Chemical fixation and solidification of hazardous wastes. New York: Van Nostrand Reinhold, 1990.

ENVIRONMENTAL PROTECTION AGENCY. Onsite Engineering Report for Waterways Experiment Station for K061. Washington, DC 1988. 
JOURNAL OFFICIEL DE LA RÉPUBLIQUE FRANÇAISE. Aretes du février 1994. NOR: ENVP $9430072^{a}$ at $3^{a}$, p. 6117-24, 1994.

MALONE, P.G.; JONES, L.W.; LARSON, R.J. Guide to the disposal of chemically stabilized and solidified waste. SW. 872, Office of Water and Waste Management. U.S Environmental Protection Agency, Washington DC, 1980

MONTGOMERY, D.C.; RUNGER, G.C. Estatística aplicada e probabilidade para engenheiros. 2. ed. São Paulo: LTC, 2003.

MULDER, E. Personal communication, TNO, Delft, The Netherlands, 2002.

SILVA, M.G. Influência da cura térmica em pastas e argamassas de cimentos de escórias de alto-forno. 1998. 232 f. Tese (Doutorado) Escola Politécnica da USP, São Paulo, 1998

SHAWABKEH, R.A. Solidification and stabilization of cadmium ions in sand-cement-clay mixture. Journal of Hazardous Materials, v. 125, n. 1-3, p. 237-243, 2005.

SHI, C.; SPENCE, R. Designing of cement-based formula for solidification/stabilization of hazardous, radioactive, and mixed wastes. Critical Reviews in Environmental Science and Technology, v. 34, n. 4, p. 391-417, jul./ago. 2004.
SPENCE, R.D.; SHI, C. Stabilization and solidification of hazardous, radioactive and mixed wastes. Boca Raton, Florida: CRC Press, 2005.

STEGEMANN, J.A.; BUENFELD, N.R. Predication of unconfined compressive strength of cement paste containing industrial wastes. Wastes management. v. 23, p. 321-332, 2003.

STEGEMANN, J.A.; CÔTÉ, P.L. Appendix B - TS-15: a cooperative program - Test methods for solidified waste evaluation. Investigation of test methods for solidified waste characterization. Burlington, Ontario: Unpublished Manuscript Series Document, 1991.

UNITED STATES ENVIRONMENTAL PROTECTION AGENCY. Method 1311. Test methods for evaluating solid waste, toxicity characteristics leaching procedure Physical/Chemical methods (SW846). Washington, DC, 1992.

WASTE WATER TECHNOLOGY CENTER. WTC-EC-EPS-3/HÁ/9. Proposed evaluation protocol for cement-based stabilization/solidification wastes. Canada: Environment Canada, 1991.

WILES, C.C. A review of solidification/stabilization technology. Journal of Hazardous Materials, n. 14, p. 5-21, 1987.

ZHANG, L. et al. Effects of sucrose and sorbitol on cement-based stabilization/solidification of toxic metal waste. Journal of Hazardous Materials, v. 151, n. 2-3, p. 490-498, 2008 